Paidéia, 2003, 13(25), 13-26

\title{
O CONCEITO FREUDIANO DE REPRESENTAÇÃO EM "SOBRE A CONCEPÇÃO DAS AFASIAS""
}

\author{
Fátima Caropreso ${ }^{2}$ \\ Universidade Federal de São Carlos
}

\begin{abstract}
Resumo: A noção de representação - uma das mais fundamentais da teoria freudiana - é objeto de uma extensa reflexão na monografia "Sobre a concepção das afasias". Nesta monografia, o autor faz uma revisão crítica das principais hipóteses sobre as afasias que predominavam na época - basicamente as do neurologista alemão Carl Wernicke - a partir das quais ele propõe uma concepção alternativa sobre o funcionamento normal e a patologia da linguagem. Como a teoria de Wernicke fundamentava-se em uma concepção específica de representação, esta acaba sendo também repensada por Freud. O objetivo deste artigo é discutir algumas das hipóteses propostas em "Sobre a concepção das afasias" e apontar as suas implicações para a formulação do conceito de representação e para o sentido que ele adquirirá no âmbito da reflexão metapsicológica.
\end{abstract}

Palavras-chave: psicanálise; Freud; metapsicologia; afasias; representação.

\section{THE FREUDIAN CONCEPT OF REPRESENTATION IN "ON THE CONCEPTION OF THE APHASIAS"}

\begin{abstract}
Representation is one of the basic concepts of Freudian theory. In Freud's monograph "On the conception of the aphasias", it is the object of extensive investigation. Here Freud reviews critically the main hypotheses about aphasias that prevailed at his time, particularly those proposed by the German neurologist Carl Wernicke. Based on this, he offers an alternative conception of the normal functioning and of the pathology of language. As Wernicke's theory was based on a specific conception of representation, this was also critically analyzed by Freud. The aim of this paper is to discuss some of the hypotheses proposed in "On the conception of the aphasias", and to point out their consequences for the concept of representation and for the sense it acquires in meta-psychological reflection.
\end{abstract}

Keywords: psychoanalysis; Freud; meta-psychology; aphasias; representation

Em sua monografia sobre a concepção das afasias de 1891, Freud faz uma revisão das principais hipóteses vigentes sobre os distúrbios afásicos e, a partir da recusa dos fundamentos epistemológicos subjacentes a tais hipóteses, ele propõe uma concepção alternativa sobre o funcionamento normal e a patologia da linguagem, apoiando-se em algumas concepções de Hughlings Jackson, Charlton Bastian e Stuart Mill. A crítica de Freud dirige-se, principalmente, à teoria de Carl Wernicke sobre as afasias e à

\footnotetext{
1 Artigo recebido para publicação em 30/09/02; aceito em 08/02/03.

2 Fátima Caropreso, Programa de Pós-Graduação em Filosofia, Universidade Federal de São Carlos, Rua das Orquídeas, 550, Cidade Jardim, São Carios, SP, Cep 13566-520, E-mail: fatimacaropreso@uol.com.br
}

teoria sobre o funcionamento do sistema nervoso de Theodor Meynert, a qual fundamentava a anterior.

Wernicke havia se tornado uma figura dominante no cenário dos estudos sobre as afasias desde a publicação de sua monografia (1977a), na qual identifica e localiza a área sensorial da linguagem na porção posterior da primeira circunvolução temporal, apoiando-se em correlações entre lesões cerebrais de tal localização e casos de afasia sensorial. A região cortical responsável pela atividade motora da linguagem, a terceira circunvolução frontal, havia sido identificada - também a partir da correlação entre sintomas e lesões cerebrais - treze anos antes por Paul Broca. Essas duas descobertas somadas possibilitaram a Wernicke a construção de um esquema 


\section{Fátima Caropreso}

explicativo da atividade da linguagem, a partir do qual os diversos casos de afasias poderiam ser esclarecidos. Os vários tipos de distúrbios afásicos foram, então, relacionados a lesões localizadas em regiões cerebrais específicas e, assim, os casos de afasia passaram a ser inteiramente explicados a partir da localização da lesão.

A dedução da localização cerebral de funções psíquicas a partir da associação entre lesões e a perda de certas funções, ou seja, a partir do método clínico-patológico, baseava-se em dois pressupostos básicos. Primeiro, na hipótese de que cada região do cérebro sedia uma função diferente e, segundo, na hipótese de que cada uma dessas funções é independente, ou seja, de que uma lesão específica pode afetar apenas uma determinada função. Freud em sua monografia sobre as afasias, de 1891 , vai procurar mostrar que, além de fundamentar-se nesses dois pressupostos básicos (a teoria de Wernicke assim como a de Meynert) ele se baseava também na hipótese de que os fenômenos neurológicos e os psicológicos possuem as mesmas propriedades, e argumenta que a teoria sobre o funcionamento normal e patológico da linguagem construída a partir de tais pressupostos é insuficiente para explicar as características dos fenômenos que pretende abordar e, a partir da recusa das teses desta teoria, procura formular uma nova concepção sobre a área e o aparelho de linguagem, apoiando-se em um modo alternativo de conceber a localização das funções cerebrais e a relação entre os fenômenos psíquicos e os neurológicos. Desses esforços resultam os contornos de uma nova concepção sobre a natureza e o modo de operação das representações, uma vez que as teorias de Meynert e de Wernicke apoiavam-se em certas concepções psicológicas - as quais parecem poder ser aproximadas do associacionismo de James Mill - a crítica às hipóteses neurológicas sobre as afasias implicou uma revisão das concepções psicológicas a elas subjacentes; nesse movimento, a concepção sobre a fisiologia e a anatomia da linguagem proposta por Freud acabou por conduzir a uma concepção consideravelmente distinta de representação.

O objetivo deste artigo é resgatar algumas das teses formuladas por Freud ao longo da sua crítica à neurologia da linguagem e comentar as suas implicações para a noção de representação. Tome- mos, para isso, como ponto de partida as teorias de Wernicke e Meynert examinadas por Freud em seu trabalho.

\section{As hipóteses neurológicas criticadas por Freud}

Para Meynert (apud Amacher, 1965), o sistema nervoso funcionaria de acordo com um mecanismo reflexo, transmitindo a excitação da periferia aferente para a eferente. Nesse processo, haveria uma etapa intermediária, que consistiria na passagem da excitação pelas fibras associativas que conectam as diferentes partes do córtex. Quando o córtex recebesse excitação de duas vias aferentes simultaneamente, haveria uma conexão entre ambas e, então, levando o influxo de excitação para outra região. $O$ córtex seria o órgão principal do cérebro, e todas as suas outras partes seus auxiliares. Ele seria constituído por duas áreas funcionalmente distintas: uma área motora, que estaria localizada na região frontal e que conteria imagens de movimento, e uma área sensorial, que estaria localizada na região temporal e que conteria imagens sensoriais. Estas duas regiões se conectariam por meio de fibras associativas - que ligam as diferentes regiões do córtex - e estariam conectadas com a periferia do sistema nervoso por meio de fibras projetivas- aquelas que conduzem as informações sensoriais da periferia do sistema nervoso ao córtex e as informações motoras no sentido inverso. Assim, todos os feixes de fibras do cérebro ou entrariam ou se originariam no córtex.

Freud (1973) comenta, em sua monografia sobre as afasias, que algumas passagens de Meynert sugerem que ele considerava que havia uma projeção ponto por ponto da periferia do corpo no córtex, mas, ao mesmo tempo, reconhece que há outras afirmações que contradizem tal ponto de vista. No entanto, Freud trata a teoria desse autor como se ela comportasse essa hipótese, o que se justifica, segundo ele, pelo fato de outros estudiosos que aceitaram os princípios da doutrina de Meynert terem propagado o conceito de uma projeção completa e topograficamente exata do corpo sobre o córtex. Os processos associativos corticais seriam os concomitantes físicos dos processos psíquicos. A informação sensorial e motora que chegasse ao córtex provocaria modificações nas células dos centros e estas se converteri- 
am nos correlatos físiologicos das representações. Segundo Freud, para Meynert, a constituição das imagens mnêmicas no córtex consistiria num processo de ocupação de células desocupadas: deste modo, deveria haver lacunas funcionais no córtex, que possibilitariam a aprendizagem.

A teoria de Wernicke (1977a) sobre as afasias consiste, como ele mesmo afirmou na abertura da sua monografia a respeito do complexo sintomático das afasias, em uma aplicação dos ensinamentos de Meynert sobre a anatomia e a fisiologia do cérebro aos processos normais da linguagem e às afasias. Em tal monografia ele propõe que a área da linguagem é constituída por um centro sensorial, um centro motor e uma região associativa que conectaria os dois centros. O primeiro giro temporal seria o centro terminal do nervo acústico e o primeiro giro frontal, incluindo a área de Broca, seria o centro terminal dos nervos que controlam a musculatura da linguagem. As imagens mnêmicas - que consistiriam em modificações permanentes do sistema nervoso central resultantes da estimulação sensorial e dos movimentos realizados - estariam armazenadas nos centros, e a associação entre essas imagens seria executada pelas fibras associativas subcorticais. De acordo com Freud, Wernicke considerava que cada uma das imagens mnêmicas individuais deveria estar contida em uma célula singular. Dessa forma, para ele, assim como para Meynert, a constituição das imagens mnêmicas consistiria num processo de ocupação de células corticais desocupadas.

Wernicke (1977a) propõe a existência de três tipos de afasias que poderiam resultar de lesões na área da linguagem: a afasia sensorial, que resultaria de lesões no centro sensorial, a afasia motora, que resultaria de lesões no centro motòr, e a afasia de condução, que resultaria de lesões nas fibras associativas que conectam esses dois centros. Em seu outro trabalho sobre as afasias, Wernicke (1977b), amplia o seu modelo para as afasias, a partir da consideração dos funcionamentos subcortical e trancortical da linguagem. Tal modificação foi influenciada por algumas hipóteses formuladas por Lichtheim no período de 1884-1885. que acrescentou ao esquema das afasias que Wernicke propusera em 1874 um centro dos conceitos, as vias subcorticais sensorial e motora e as vias transcorticais sensorial e motora, as quais seriam exclusivas da linguagem. Wernicke adotou a proposta de Lichtheim e introduziu, na sua monografia de 1885 , quatro outros tipos de afasias: as afasias sensorial e motora subcorticais e as afasias sensorial e motora trancorticais. Contudo, somente para o centro sensorial, para o centro motor e para a região associativa situada entre esses centros, ele continuou estabelecendo uma localização anatômica precisa.

\section{As hipóteses psicológicas implícitas na teoria neu- rológica de Meynert e Wernicke}

Meynert e Wernicke consideravam que os fenômenos psíquicos eram correlatos dos fenômenos neurológicos, embora, na maior parte das vezes, falassem desses dois tipos de fenômenos como se eles fossem idênticos. Sendo assim, a representação simples para Meynert e para Wernicke - pelo menos se consideramos somente o modo como Freud expõe a teoria desses autores - seria o correlato de um engrama contido em uma célula singular de um centro cerebral, e este engrama, por sua vez, seria uma cópia dos estímulos que incidissem sobre a periferia do sistema nervoso, já que os mesmos seriam projetadọs no córtex sem sofrer nenhuma alteração ao longo deste percurso. Os correlatos físicos das representações complexas resultariam de associações mecânicas entre os correlatos das representações simples, e esta associação seria determinada, primeiramente, pela simultaneidade da incidência dos estímulos sobre o sistema nervoso. Deste modo, a mente seria dotada de um funcionamento totalmente passivo, pois tanto a constituição dos correlatos das representações simples como dos correlatos das representações complexas seriam inteiramente determinados por fatores externos.

Forrester (1983) afirma que a concepção sobre o funcionamento do sistema nervoso que fundamentava a teoria localizacionista das afasias apoiava-se na teoria psicológica associacionista. Amacher (1965) sugere que é pertinente comparar a visão de James Mill sobre os processos fundamentais da mente com a visão de Meynert e que, embora Meynert não tenha baseado explicitamente sua psicologia em James Mill, ele pode ter derivado suas suposiçōes psicológicas de outros autores germânicos que incor- 


\section{Fátima Caropreso}

poraram algumas das visões da tradição britânica em seus trabalhos.

Para James Mill (Herrnstein \& Boring, 1971), a mente receberia e associaria os estímulos que chegam aos órgãos sensoriais, e essa associação se daria de acordo com a contigüidade da recepção desses estímulos, ou seja, sem uma intervenção ativa do funcionamento mental. Os objetos externos nos enviariam impressões sensoriais, e estas se agrupariam em nossa mente em virtude da contigüidade de sua formação. As representações complexas consistiriam em agregados de representações simples, que resultariam de conexões mecânicas e, portanto, todas as propriedades das primeiras já estariam presentes nas últimas, isto é, as propriedades da representação complexa consistiriam na soma das propriedades dos elementos que a compõem. Segundo Amacher (1965), Meynert procurou descrever os concomitantes nervosos para os processos psíquicos que os psicólogos associacionistas haviam descrito.

A crítica freudiana vai se opor, praticamente, a cada um dos tópicos da teoria neurológica de Meynert e de Wernicke e, consequientemente, às hipóteses psicológicas a ela subjacentes. Passemos, portanto, à análise de alguns dos argumentos usados por Freud para sustentar uma concepção sobre a área e o aparelho de linguagem distinta daquela que se pode encontrar na perspectiva localizacionista e que implicará na proposição de uma noção alternativa de representação.

\section{A desconștrução do esquema de Wernicke das afasias}

Freud analisa um a um os segmentos do esquema de Lichtheim mencionado acima - o qual fora, no essencial, endossado por Wernicke - e procura afastar todas as hipóteses que pudessem ser refutadas por dados clínicos e todas as que tivessem sido inferidas de maneira arbitrária. Ele suprime deste esquema tudo o que não se mostrou capaz de resistir a esse trabalho crítico, e as partes que foram mantidas são apontadas como as verdadeiras constituintes da área da linguagem. A recusa da diferenciação entre centros e vias associativas da linguagem, a recusa da noção de lacunas funcionais e da idéia de projeção ponto por ponto da periferia no córtex são as que têm consequiências mais importantes para o conceito de representação, por isso, o comentário da crítica empreendida por Freud que se segue irá restringir-se a esses pontos.

No início da sua monografia, Freud aponta que a hipótese da afasià central pode ser considerada supérflua, dado que uma lesão na totalidade das vias de acesso tornaria o centro inacessível e, portanto, seria clinicamente equivalente à lesão ou destruição deste centro. Mas é necessário, para descartar de fato a hipótese dos centros de linguagem, negar a função que lhes foi atribuída, isto é, recusar que é preciso haver locais de armazenamento das impressões sensoriais e motoras da linguagem no córtex, o que Freud faz no quinto capítulo, ao revisar algumas hipóteses de Meynert que, como já foi dito, estavam pressupostas e consistiam no fundamento da teoria de Wernicke.

Freud argumenta que a hipótese de Meynert da existência de centros cujas células armazenariam as diversas impressões sensoriais e motoras fundamentava-se na suposição de que os fenômenos neurológicos e os psíquicos deveriam possuir as mesmas características, pois a um simples psíquico - uma impressão sensorial - corresponderia um simples neurológico - um engrama contido em uma célula. Freud argumenta que essa transposiçăo de termos psicológicos em termos neurológicos, empreendida por Meynert e mantida por seus seguidores, é um procedimento arbitrário, pois os fenômenos psíquicos e os neurológicos não precisam apresentar necessariamente as mesmas características. Ele, então, recusa a suposição de que cada uma das imagens sensoriais estariam armazenadas em uma célula de um dos centros corticais:

"Na psicologia, a idéia simples é para nós algo elementar que podemos diferenciar claramente de sua conexão com outras idéias. Esta é a razão por que nos sentimos tentados a presumir que o seu correlato fisiológico, a dizer, a modificação das células nervosas que se originam pela estimulação das fibras nervosas, seja também algo simples e localizável. Tal inferência, com certeza, carece de todo fundamento; as qualidades dessa modificação têm que ser estabelecidas em si mesmas e independentemente de seus concomitantes psicológicos." ( Freud, 1973, p.70) 
Freud reconhece que o fato de Wernicke ter declarado que somente os elementos psíquicos mais simples, ou seja, as distintas percepções sensoriais, poderiam ser localizadas no córtex é um progresso, se considera-se a tendência anterior da medicina de localizar mesmo as faculdades mentais mais complexas, mas argumenta que, em princípio, Wernicke comete o mesmo erro dos seus predecessores:

“...não se comete por acaso, em princípio, o mesmo erro tanto quando se pretende localizar um conceito complicado como toda uma faculdade ou um elemento psíquico? É justificado submergir uma fibra nervosa, que ao longo de todo o seu curso havia sido somente uma estrutura fisiológica sujeita a modificações fisiológicas, com sua terminação no psíquico e dotar esta terminação de uma idéia ou recordação?" (Freud, 1973, p.69)

Nessa passagem, Freud parece referir-se à teoria de seus opositores como se esta se baseasse na hipótese de que os fenômenos psíquicos e os físicos são idênticos. Mas, em seguida, ele reconhece que, na verdade, tais autores consideravam que as modificações neurológicas das fibras nervosas mediante os estímulos sensoriais produziriam outras modificações nas células nervosas centrais, as quais, então, se converteriam no correlato fisiológico da idéia. $\mathrm{Ou}$ seja, para Meynert e para Wernicke, as modificações nas células corticais seriam tão somente os correlatos das idéias e não as próprias idéias. Freud argumenta que a insuficiência do conhecimento a respeito dos processos fisiológicos levou estes autores a empregarem termos psicológicos para referir-se a fenômenos fisiológicos, misturando assim esse dois domínios, e que é necessário estabelecer um limite preciso entre os fenômenos neurológicos e os psíquicos, necessidade esta que já havia sido apontada por Hughlings Jackson. Diante disto, Freud adota a mesma posição de Jackson: ele propõe que se considere que os fenômenos psíquicos e os físiológicos sejam concomitantes dependentes:

"A relação entre a cadeia de processos fisiológicos que se dão no sistema nervoso $e$ os processos mentais provavelmente não é de causa e efeito. Aqueles não cessam quando estes começam; tendem a continuar, porém, a partir de um certo momento, um fenômeno mental corresponde a cada parte da cadeia ou a várias partes. O processo psíquico é, portanto, paralelo ao fisiológico, um concomitante dependente." (Freud,1973, p.70)

De acordo com a doutrina da concomitância, formulada por Jackson (1958), os estados mentais ou conscientes e os estados nervosos ocorreriam paralelamente, mas não haveria interferência de um sobre o outro. Para cada estado mental, haveria um estado nervoso correlativo. Citando um exemplo dado por Jackson: em uma percepção visual, há um circuito físico da periferia sensorial para os centros superiores $\mathrm{e}$, destes, retornando à periferia muscular. A imagem visual, que é um estado puramente mental, surge durante as (e não das) atividades dos dois elos superiores dessa corrente puramente física. A natureza dessa relação, contudo, não chega a ser definida.

Essa posição de Jackson visa conferir autonomia ao seu objeto de estudo e lhe permitir distanciar-se da confusão entre o que é físico e o que é psíquico mencionada acima. Forrester (1983) comenta que um dos primeiros ataques aos 'fazedores de diagramas' ${ }^{3}$ proveio de uma reunião de argumentos psicológicos e filosóficos, no trabalho de Jackson. Este estava interessado em romper com a flutuação entre termos psicológicos e fisiologicos que afetava as teorias sobre as afasias, assim como a neurologia em geral. De acordo com Forrester, a doutrina da concomitância - um argumento firme para uma separação estrita entre os processos psíquicos e os físicos - protegeu a neurologia contra um psicologismo rasteiro. Diante da necessidade de tratar os processos psíquicos e os fisiológicos como dois tipos de fenômenos independentes, Freud adota a concepção de Jackson, segundo a qual esses dois processos, embora concomitantes, não interferem um sobre 0 outro.

Desse modo, ao sustentar que os correlatos de uma idéia simples se localizam em algo simples, ou

\footnotetext{
${ }^{3}$ Esse termo foi usado por Henry Head para se referir aos neurologistas que procuravam explicar os distúrbios afásicos e o funcionamento da linguagem a partir de diagramas, como Wernicke, Lichtheim e outros.
} 


\section{Fátima Caropreso}

seja, em uma célula cortical, Meynert teria atribuído as propriedades do fenômeno psíquico ao fenômeno neurológico, ou seja, ele teria se apoiado no pressuposto de que esses fenômenos possuem as mesmas propriedades. Freud nega a legitimidade de tal procedimento - dessa transposição das hipóteses da psicologia associacionista para a neurologia, apontada por Amacher - e procura formular uma hipótese alternativa que seja capaz de contornar o que lhe parece um equívoco. Segundo Marx (1967), o que há de mais importante da monografia de Freud sobre as afasias é o fato de ela ter apontado a ilogicidade de se construir um modelo anatômico a partir de uma concepção psicológica, identificando, assim, uma das maiores falácias inerentes às principais formulações psicofisiológicas da época. Após essa crítica, Freud se pergunta qual é, então, o correlato fisiológico da idéia simples e responde:

"Obviamente, nada estático, mas algo que tenha o caráter de um processo. Este processo não é incompativel com a localização. Começa em um ponto específico do córtex e, a partir dai, se difunde por todo o córtex e ao longo de certas vias. Quando este fato ocorre, deixa atrás de si uma modificação, com a possibilidade de uma recordação na parte do córtex afetada". (Freud, 1973, p.71)

Dessa forma, Meynert e Wernicke teriam reduzido as antigas faculdades propostas por Franz Gall a agregados de impressões sensoriais e motoras elementares, e Freud passara a considerar essas impressões elementares como algo muito mais complexo, ou seja, como um conjunto de intrincados processos associativos. Provavelmente, Freud baseou estas hipóteses na concepção de Jackson (1958) de que a idéia é o correlato de um processo sensório-motor: o correlato fisiológico de uma idéia simples seria um processo e não um engrama contido em uma célula individual. Para Freud, então, o simples do ponto de vista psíquico deve corresponder a um complexo do ponto de vista neurológico. Disto segue-se que não é possível diferenciar os correlatos fisiológicos da associação e da representação, pois o correlato de uma idéia simples é sempre um processo associativo, ou seja, para haver representação é necessário que haja associação. Com isso, a associação deixa de ser considerada um processo que se dá entre os correlatos das representações simples, levando à constituição dos correlatos da representação complexa, e passa a ser a condição necèssária de todo correlato da representação. Como consequiência, a noção de centros de linguagem perde seu sentido: se não há correlatos de representações armazenados em células corticais, não é necessário haver locais de armazenamento, isto é, os centros de linguagem. A diferenciação anatômica e funcional entre centros e vias associativas é, com isso, recusada. A área da linguagem seria, portanto, uma área exclusivamente associativa.

A outra hipótese, cuja recusa terá conseqüências importantes para o conceito de representação é a da existência de áreas desocupadas, onde as imagens mnêmicas iriam sendo acumuladas. Freud emprega dois argumentos contra esta hipotese das lacunas funcionais. $O$ primeiro refere-se ao modo como a existência dessas lacunas foi inferida. De acordo com ele, as áreas que apresentavam a maior superposição de lesões nos exames post mortem foram consideradas como sendo centros de linguagem, ou seja, como as áreas cuja integridade seria indispensável para que a linguagem funcionasse normalmẹte. As demais áreas foram, por exclusão, consideradas regiões sem função. Freud argumenta que tal inferência não é correta, porque pode perfeitamente haver outras áreas corticais que também estejam a serviço da linguagem, ainda que sua destruição possa ser tolerada mais facilmente e, além disso, também é possível que uma lesão em uma região provoque uma alteração no funcionamento de outra região, ou seja, uma lesão pode provocar uma alteração funcional mais ou menos generalizada. Por isso, apenas o fato de lesões de determinadas áreas não estarem associadas a casos de afasia não permite concluir que essas regiões não sejam responsáveis por nenhuma função da linguagem, que elas consistam nas chamadas lacunas funcionais.

O segundo argumento de Freud dirige-se contra a função que foi atribuída a tais lacunas, ou seja, dirige-se contra a hipótese de que a aprendizagem da linguagem consistiria num processo de ocupação de regiões desocupadas. Usando a analogia empregada por Freud para expressar a concepção de aprendiza- 
gem de Meynert, esta ocorreria de uma maneira similar à expansão de uma cidade quando as pessoas se instalam nas áreas que estão fora de suas murathas. Freud argumenta que, se examinamos a utilidade desta hipótese para a compreensão dos distúrbios afásicos, vemos que o que ocorre é exatamente o oposto do que pode ser previsto pela suposição das lacunas funcionais. Se a aprendizagem ocorresse da forma como considerava Meynert, deveria ser possível, no caso de uma lesão na área da linguagem, que a língua materna fosse prejudicada e uma adquirida, posteriormente, permanecesse intacta, pois cada uma delas estaria armazenada em uma área diferente. Mas, argumenta Freud, jamais acontece que uma lesão orgânica afete a língua materna e não afete uma língua aprendida posteriormente; o que invariavelmente ocorre, em todas as funções da linguagem, é o contrário. Ele diz que, ao revisar o material pertinente, nota-se que dois fatores determinam o caráter do transtorno de linguagem em poliglotas - a influência da idade de aquisição da língua e a influência da prática - e que esses fatores operam sempre na mesma direção. O prejuízo da linguagem segue a ordem contrária à da aprendizagem, ou seja, as línguas posteriormente adquiridas são as primeiras a serem afetadas, a não ser que uma língua adquirida mais tarde tenha sido mais usada que a materna. Portanto, pode-se inferir que:

“(...) um novo conjunto de associações pode sobrepor-se às associações já estabelecidas que intervêm na fala(...) O conjunto de associações sobrepostas é danificado antes que o primário, seja qual for a localização da lesão." (Freud,1973, p.75)

Deste modo, a aprendizagem da linguagem não parece consistir num processo de ocupação de áreas desocupadas e sim num processo sobre-associação, no qual todas aquisições da linguagem se dão na mesma área, com as associações sobrepondo-se umas às outras. Sendo assim, torna-se desnecessário supor a existência das lacunas funcionais, e esta hipótese também pode ser descartada por Freud.

Após afastar uma a uma as hipóteses de Wernicke sobre as diferenciações na área da linguagem, Freud conclui que esta é uma área cortical homogênea, exclusivamente associativa, situada no hemisfério esquerdo entre as terminações dos nervos acústicos, óticos e motores. Haveria uma via subcortical motora exclusiva da linguagem, mas um dano nesta via provocaria um problema de articulação que não caracterizaria um distúrbio afásico; assim, a afasia, para Freud, decorreria de um processo unicamente cortical. Uma vez que a área da linguagem seria homogênea, os processos que nela ocorressem é que determinariam as diferenciações. Dessa forma, a anatomia não determinaria o funcionamento da linguagem; ao contrário, ela estaria subordinada a este funcionamento.

Freud não apenas recusa o esquema das afasias de Wernicke e Lichtheim, como descarta também os pressupostos básicos da teoria desses autores, sem os quais suas hipóteses se tornariam insustentáveis. Ele sustenta que uma mesma área pode abrigar mais de uma função e que as diferentes funções não são independentes umas das outras - o que tem como conseqüência que lesões de mesma localização possam provocar quadros clínicos diferentes e vice-versa. Dessa forma, não seria possível inferir a função abrigada por uma área cortical específica apenas a partir da relação entre os sintomas afásicos e a lesão; não seria possível explicar o distúrbio apenas a partir da localização da lesão, nem a partir desta tirar conclusões precisas a respeito do quadro clínico. Além disso, uma vez que se considera que o simples do ponto de vista psicológico corresponde a um complexo do ponto de vista neurológico - ou seja, que uma idéia simples corresponde a um processo associativo -, não há como falar de engramas armazenados no córtex e, portanto, de áreas de armazenamento, isto é, de centros sediando exclusivamente cada uma das diversas funções da linguagem.

A hipótese formulada por Freud sobre a área da linguagem apresenta-se, assim, como uma concepção alternativa da localização das funções cerebrais e da relação entre os fenômenos psíquicos e os fisiológicos. A hipótese subjacente à teoria de Wernicke sobre a localização de funções cerebrais compostas é em parte aceita, pois Freud aceita que o cérebro não atua como um todo, sendo funcionalmente composto, e em parte recusada, pois Freud recusa a hipótese de que cada uma das funções da lingua- 


\section{Fátima Caropreso}

gem localize-se em uma área diferente e que todas funções sejam independentes umas das outras. Segundo ele, não é necessário haver centros que sediem as diferentes funções da linguagem: algumas dessas funções podem estar localizadas numa mesma área $\mathrm{e}$ parte delas são funcionalmente dependentes umas das outras. Freud propõe, então, que só é possível estabelecer a região onde transcorrem os processos correlativos às funções psíquicas, ou seja, que apenas é possível falar de uma área da linguagem e não de centros e vias associativas da linguagem. Vejamos, agora, de que forma, Freud concebe o aparelho de linguagem - noção esta que descreve o conjunto de processos relativos à linguagem - que tal área abrigaria.

\section{$O$ aparelho de linguagem proposto por Freud}

Os processos associativos que se dariam na área da linguagem constituiriam o aparelho de linguagem. Tais processos consistiriam no último estágio da série de reorganizações sucessivas da informação sensorial proveniente do mundo externo. Segundo Freud, os estímulos que incidissem sobre a medula seriam reordenados ao longo do seu caminho até o córtex, onde eles passariam por outro processo associativo e, então, seriam mais uma vez reorganizados. Os complexos associativos formados por esses processos corticais possuiriam concomitantes psíquiços que, no caso da área da linguagem, consistiriam nas representações de palavra e, nas demais regiões corticais, nas representações de objeto.

Freud formula essa hipótese da reorganização funcional dos estímulos em substituição à idéia de Meynert de que haveria uma projeção topograficamente exata da periferia do corpo no córtex. Ele recusa duas hipóteses que seriam condições necessárias para a ocorrência dessa projeção ponto a ponto: primeiro, a de que o número de fibras que parte da periferia é idêntico ao que ingressa no córtex; segundo, a de que na passagem dessas fibras pelos núcleos de matéria cinzenta, não há alteração de nenhuma espécie no material conduzido.

Contra a primeira dessas hipóteses, é mencionada uma constatação de Henle, segundo a qual o número de fibras que conecta a periferia do sistema nervoso à medula é maior que o número de fibras que conecta esta última ao cérebro. Portanto, de acordo com as características anatômicas do sistema nervoso, só entre a periferia e a medula seria possível haver uma projeção ponto por ponto dos estímulos. Devido a essa redução do número de fibras na passagem pela medula, uma unidade sensorial que alcançasse o cérebro deveria corresponder a várias das unidades sensoriais que alcançassem a periferia. Sendo assim, haveria, forçosamente, uma reorganização da informação sensorial ao longo de sua condução ao córtex. A partir disso, Freud propõe que a relação entre a periferia do sistema nervoso e a medula pode ser chamada de projetiva, como queria Meynert, mas a relação entre esta e o córtex deve ser chamada de representativa:

"(...) uma unidade de substância cinzenta que pertence a um nivel superior não pode corresponder a uma unidade periférica, mas tem que estar relacionada com várias de tais unidades. Isto também vale para o córtex cerebral e é, portanto, adequaáo empregar termos diferentes para esses dois tipos de representação no sistema nervoso central. Se chamamos "projeção" ao modo como a periferia está refletida na medula espinhal, sua contraparte no córtex cerebral poderia convenientemente ser chamada uma "representação"(Repräsentation), o que implica que a periferia do corpo não está contida ponto por ponto no córtex cerebral e sim por fibras selecionadas com uma diferenciação menos detalhada". (Freud, 1973, p.66)

Contra a segunda condição necessária para a projeção ponto por ponto dos estímulos - ou seja, contra a hipótese de Meynert de que as fibras retêm sua identidade mesmo após atravessar vários núcleos de matéria cinzenta - Freud argumenta que as várias fibras provenientes de diferentes partes do sistema nervoso se conectam nesses núcleos e que a cada fibra aferente correspondem várias fibras eferentes, em um mesmo núcleo. Dessa forma, não é possível que a informação aferente seja exatamente igual à eferente: 
"Se seguimos o curso de um feixe sensorial aferente tal como o conhecemos e consideramos como características suas freqüentes interrupções nos núcleos cinzentos e sua arborização através deles, podemos supor que o significado funcional de uma fibra muda ao longo do seu caminho até o córtex cerebral cada vez que ela emerge de um núcleo".(Freud, 1973, p.67)

Portanto, no caminho da medula ao córtex, o material sensorial seria sucessivamente reordenado de acordo com os princípios funcionais do sistema nervoso. Assim, os estímulos que chegassem ao córtex - isto é, o material constituinte dos correlatos das representações - possuiriam uma relação muito indireta com os estímulos periféricos, e o processo associativo cortical faria um último rearranjo nesse material, tornando esta relação ainda mais indireta. Desta forma, os correlatos das representações consistiriam no estágio final de um processo de reordenação da informação periférica e, sendo assim, as nossas representações corresponderiam apenas ao ápice desse processo, de forma que nós desconheceríamos todas as suas determinações anteriores:

"(...) os feixes de fibras, que chegam ao córtex cerebral depois de haver passado por outras massas cinzentas, mantêm alguma relação com a periferia do corpo, porém já não refletem uma imagem topograficamente exata dela. Contêm a periferia do corpo da mesma maneira que - para tomar um exemplo do tema que nos interessa aqui - um poema contém o alfabeto, isto é, uma disposição completamente diferente que está a serviço de outros propósitos, com múltiplas associações dos elementos individuais nas quais alguns podem estar representados várias vezes e outros estar totalmente ausentes." (Freud, 1973, p.68)

É provável que Freud tenha baseado essa hipótese sobre a reorganização dos estímulos periféricos na teoria de Jackson (1958). Segundo este autor, o sistema nervoso consistiria num mecanismo sensório-motor, da base ao topo, no qual seria possível diferenciar três níveis de evolução: os centros inferiores, os "intermediários" e os "superiores'. Os centros sensório-motores superiores evoluiriam a partir dos intermediários; estes, a partir dos inferiores, e estes, por sua vez, a partir da periferia. Cada um deles representaria o mesmo material do nível inferior, de uma forma diferente, além de incluir novos materiais. Portanto, as informações sensoriais e motoras seriam sucessivamente reordenadas, e o último nível de organização consistiria na base física dos processos psíquicos, de forma que estes só poderiam representar de forma triplamente indireta as informações da periferia.

Em suma, para Freud, o aparelho de linguagem seria constituído por processos associativos entre elementos acústicos, cinestésicos e visuais, que consistiriam no último estágio de reorganização dos estímulos periféricos. Haveria dois processos distintos nesse aparelho, o fisiologico e o psíquico, que transcorreriam paralelamente. Do ponto de vista fisiológico, o aparelho seria constituído por processos associativos funcionalmente similares, que se sobreporiam uns aos outros, ou seja, que se sobre-associariam. Dessa forma, haveria vários níveis de funcionamento coexistindo no aparelho de linguagem, cada um dos quais corresponderia a momentos diferentes do desenvolvimento do indivíduo. Do ponto de vista psicológico, o aparelho de linguagem seria constituído por representações de palavra, que, embora funcionassem como uma unidade, consistiriam em complexos constituídos por imagens acústicas, visuais, quirocinestésicas e glossocinestésicas. Esta hipótese sobre os elementos constituintes da palavra já estava presente em Wernicke e em outros neurologistas a ele contemporâneos, como Grashey, Bastian e Déjerine. $O$ que pode ser considerado novo na concepção de Freud sobre a representação de palavra é o modo como ele pensa os processos associativos ${ }^{1}$ que se dão entre seus elementos constituintes:

\section{"Do ponto de vista psicológico, a "palavra" é a unidade funcional da linguagem: é uma representação complexa constituída por ele- mentos acústicos, visuais e cinestésicos.}

\footnotetext{
"Freud usa o termo "associação" para se referir tanto aos processos fisiológicos como aos psicológicos.
} 


\section{Fátima Caropreso}

Devemos o conhecimento desta estrutura à patologia, a qual demonstra que as lesões orgânicas que afetam o aparelho de linguagem ocasionam uma desintegração da linguagem correspondente a tal constituição... Geralmente se consideram quatro constituintes da representação de palavra: a "imagem acústica" ou "impressão acústica", a "imagem visual da letra" e as "imagens ou impressões "glossocinestésicas e quirocinestésicas", porém esta constituição parece ainda mais complicada se se considera o provável processo de associação implícito nas diversas atividades da linguagem". (Freud, 1973, p.86)

A imagem acústica seria a primeira a se formar; em seguida, formar-se-iam a imagem glossocinestésica, a imagem visual da letra e, por último, a quirocinestésica. Todas as imagens se associariam à acústica; portanto, ao menos inicialmente, todas as atividades da linguagem dela dependeriam. A fala espontânea ou a repetitiva e a compreensão das palavras permaneceriam sempre dependentes da imagem acústica, uma vez que a imagem cinestésica só seria acessada por meio dela e uma vez que seria apenas por meio da imagem acústica que a representação de palavra se associaria à representação de objeto e que, desta associação, dependeria o significado das palavras - Freud afirma que, ao menos no caso dos substantivos, é a representação de objeto que atribui significado à representação de palavra.

A representação de objeto consistiria também num complexo associativo, mas tal complexo não seria constituído apenas por representações acústicas, visuais e cinestésicas, como a representação de palavra; outros tipos de imagens (tácteis, olfativas, etc.) poderiam vir a integrá-lo. A representação de objeto, assim como a de palavra, possuiria como correlato um processo associativo, que consistiria no último estágio de reorganização do material perceptivo, pois a concepção de Freud sobre o processo de condução dos estímulos da periferia ao córtex não se restringe às informações relacionadas à linguagem, mas refere-se ao processo de condução do material perceptivo em geral. Além da representação de objeto ser constituída por uma variedade maior de elementos sensoriais, a possibilidade de novos elementos se acrescentarem a ela nunca cessaria, ao contrário da representação de palavra. Uma vez que as imagens acústicas, visuais e cinestésicas de uma determinada palavra se constituíssem, não haveria novos elementos a serem acrescentados àquela representação.

Novas representações de palavra poderiam constituir-se e associar-se às anteriores, mas não seria possível que percepções diferentes da mesma fossem experienciadas. Mas, com relação à representação de um objeto específico, sempre haveria a possibilidade de que, por exemplo, percep̧̧ões visuais de diferentes ângulos ou percepções tácteis de suas diferentes partes fossem experienciadas e, assim, acrescentassem novos elementos à representação. É por isso que Freud afirma que, enquanto a representação de palavra seria um complexo fechado, a representação de objeto seria um complexo aberto, pois sempre haveria a possibilidade de que novos elementos se acrescentem aos anteriores.

Esta concepção de objeto proposta por Freud provém, em parte, da concepção de objeto de Mill (1974). Segundo este, quando dois fenômenos que nunca foram experienciados ou pensados separadamente fossem experienciados juntos com muita frequiência, produzir-se-ia entre eles uma associação inseparável, a qual tornaria impossível pensar os dois fenômenos isoladamente, a não ser que alguma experiência subseqüente viesse dissolver a associação. De tal associação inseparável e da capacidade de expectativa da mente humana - a capacidade que possuímos de, após ter sensações reais, conceber que novas sensações podem vir a ser experienciadas em associação com as anteriores e que, dado certas condições, as mesmas sensações podem retornar - resultaria a idéia de um objeto externo, segundo Mill. Segundo ele, essa concepção de sensações possiveis apresentaria um caráter de permanência que se oporia ao caráter efêmero de nossas sensações e, a partir dessa diferenciação, seríamos levados a considerar que ambás são coisas diferentes, que as possibilidades de sensações existem independentes de nós, ou seja, que existem objetos externos, dos quais essas sensações provêm. Ao expor sua concepção de objeto, Freud menciona esta idéia de Mill. Diz ele: 
"A idéia, ou conceito, de objeto é ela mesma outro complexo de associações composto pelas mais diversas impressões visuais, acústicas, cinestésicas e outras. Segundo o ensinamento da filosofia, a idéia de objeto não contém outra coisa; a aparência de uma "coisa", cujas "propriedades" nos são transmitidas por nossos sentidos, se origina somente do fato de que ao enumerar as impressões sensoriais percebidas de um objeto deixamos aberta a possibilidade de que se acrescente uma grande série de novas impressões à cadeia de associações (J. S. Mill)". (Freud, 1973, p.90)

Tanto para Freud como para Mill, a representação de objeto consistiria num complexo de impressôes sensoriais e, portanto, nossa idéia de uma coisa no mundo só poderia ser uma inferência que se originaria desse agregado de impressões e da nossa capacidade de expectativa.

Então, o aparelho de linguagem consistiria em vários níveis de processos associativos neurológicos concomitantes a vários níveis de processos associativos psicológicos, os quais constituiriam as representações de palavra. Vejamos, por fim, quais consequiências para a formulação de um conceito de representação são acarretadas por essa teoria sobre a fisiologia e a psicologia da linguagem proposta por Freud.

\section{A Representação segundo Freud}

Em primeiro lugar, uma vez que Freud propôs que o simples do ponto de vista psíquico corresponde a um complexo do ponto de vista neurológico, uma imagem - uma representação simples - deve corresponder a um processo associativo e uma representação complexa, como a da palavra, deve corresponder, portanto, a uma rede de processos associativos. Deste modo, nos correlatos da representação, não é possível diferenciar algo simples, estes só existem enquanto complexos, pois só com a associação surge o correlato de uma representação. Mas, do lado psicológico, há representações simples e representações complexas, que resultam da associ- ação das primeiras. Freud usa, para se referir aos elementos constituintes da representação de palavra, tanto o termo "Bild" (imagem) como "Vorstellung"(representação), termo este que é sempre usado para se referir à representação de palavra (Wortvorstellung) e à de objeto (Objektvorstellung). Por exemplo, para se referir à imagem de movimento da fala, ele usa tanto "Sprachbewegungsvorstellung" como "Sprachbewegungsbild". Dessa forma, enquanto do ponto de vista fisiológico a associação é o processo constituinte dos correlatos das representações, do ponto de vista psicológico, a associação continua sendo um processo que se dá entre as representações simples para a constituição das representações complexas, ou seja, nesse sentido, a associação continua sendo concebida de uma forma próxima como o era pela psicologia associacionista.

O conceito de associação proposto por Freud, no entanto, parece se distanciar da mecânica mental de James Mill e se aproximar da química mental de Stuart Mill. Uma vez que as representações se sobreassociariam umas às outras e que, nesse processo, 0 complexo associativo não apenas se expandiria, mas se reorganizaria, adquirindo, assim, novas características, as propriedades da representação complexa não consistiriam na mera soma das propriedades das representações simples que a compõem; novas propriedades emergiriam no complexo. Dessa forma, como para Stuart Mill, a associação seria um processo análogo à sintese química. Não seria possível inferir as características da representação complexa a partir da análise das características dos seus elementos constituintes tomados isoladamente.

Uma segunda característica da representação é o fato dela consistir numa construção mental, e não numa cópia das sensações. A informação sensorial é sucessivamente reorganizada ao longo do seu percurso da medula ao córtex e, aí, como vimos, ela sofre um último processo de reorganização; portanto, os correlatos das nossas representações seriam construções do sistema nervoso, rearranjos da informação recebida do mundo externo, de acordo com os princípios funcionais deste sistema. Deste modo, pode-se dizer que nossas representações seriam constituídas por um funcionamento inato a partir de um conteúdo adquirido. Nesse ponto, Freud claramente 


\section{Fátima Caropreso}

se distancia dos autores associacionistas mencionados acima, pois, para estes, nenhum fator subjetivo interferiria na construção de nossas representações; a mente seria mera receptora passiva das informações sensoriais. Uma vez que, para Freud, o que se torna consciente é o correlato de um processo que representa o último estágio de reorganização da informação sensorial, nossas representações corresponderiam ao ápice de um processo cujos estágios anteriores nos seriam totalmente inacessíveis. Nós não teríamos conhecimento das etapas da construção das nossas representações, nem de suas determinações, o que implicaria reconhecer que só temos acesso aos estímulos provenientes do mundo externo de uma forma muito indireta, através de uma série de mediações.

As representações de palavra se sobre-associariam umas às outras, de forma que vários níveis de processos associativos, correspondentes aos diferentes estágios do desenvolvimento do sujeito, coexistiriam. Nesse processo de sobre-associação, as representações mais antigas transfeririam seu significado às mais recentes, formando-se, assim, séries associativas de mesma significação. Como a representação de palavra, ao menos no caso dos substantivos, adquiriria seu significado a partir da sua associação com a representação de objeto, haveria várias cadeias de representações de palavra que, em última instância, denotariam o mesmo objeto. Sendo assim, para conhecermos o significado real de uma palavra, seria necessário percorrer essa cadeia no sentido inverso ao da sua constituição, pois só assim seria possível chegar à representação de objeto que lhe conferiu significado, isto é, ao significado originário da palavra.

Um último aspecto da representação a ser considerado é sua relação com a consciência. Freud considera, no ensaio sobre as afasias, que o psíquico restringe-se ao consciente e, consequientemente, que toda representação é, por natureza, consciente. Os correlatos das representações seriam processos associativos que deixariam atrás de si modificações, as quais possibilitariam a rememoração. Mas só quando o mesmo processo voltasse a ocorrer a representação emergiria novamente. Dessa forma, as modificações corticais seriam condições necessárias para a representação, mas não suficientes. Ao falar sobre os processos associativos correlatos das representações, Freud afirma:

"Este processo não é incompativel com a localização. Começa em um ponto específico do córtex e a partir dai se difunde por todo o córtex e ao longo de certas vias. Quando este fato tem lugar, deixa atrás de si uma modificação, com a possibilidade de uma recordação na parte do córtex afetada. É muito duvidoso que esse fenômeno fisiológico esteja de algum modo associado com algo psíquico. Nossa consciência não contém nada que possa justificar, do ponto de vista psicológico, $O$ termo "imagem latente de recordação". No entanto, cada vez que o mesmo processo cortical volta a ser suscitado, of fenômeno psiquico anterior emerge novamente como recordação". (Freud, 1973, p.71, grifo do autor)

Portanto, nesse texto, o psíquico é identificado com a consciência e só é possível falar de inconsciente para designar uma ausência de consciência que implicaria também a ausência de fenômenos psíquicos. Essa identificação entre o psíquico e o consciente será abandonada por Freud (1995), já no projeto de uma psicologia. Nesse texto, Freud expande a noção de psíquico em relação à de consciência, e esta última passa, então, a ser concebida como algo que pode ou não acrescentar-se a uma representação. Assim, a inconsciência passa a ser não só a condição predominante das representações, mas também o seu estado originário.

\section{Conclusão}

A noção de representação, que, sem dúvida, é uma das mais centrais da teoria freudiana, não volta a receber tratamento tão sistemático na obra posterior de Freud como o que é desenvolvido em "Sobre a concepção das afasias". Neste texto, a reformulação da teoria sobre a neurologia e a psicologia da linguagem empreendida pelo autor acaba por levar à formulação de um conceito de representação que se distancia em alguns aspectos do que estava subentendido nas teorias criticadas. Ao invés de ser uma cópia dos estímulos que chegam à periferia do sistema ner- 
voso, a representação, para Freud, seria uma construção do sistema nervoso. Ao invés de um processo de expansão topográfica, a constituição da representação consistiria num processo de sobre-associação, onde o significado das representações seria transferido das mais antigas para as mais recentes, formando-se, assim, cadeias associativas de mesma significação. Ao invés de ser o correlato de um engrama contido em uma célula cortical, a representação simples passa a ser concebida como o correlato de um processo associativo e, com isso, a distinção entre representação e associação desaparece no nível neurológico. No entanto, a identificação entre o psíquico e a consciência e, portanto, entre representação e consciência é ainda mantida nesse texto. Freud sustenta aí que os processos psíquicos são concomitantes, dependentes de certos processos nervosos e recusa, claramente, a existência de um psíquico inconsciente. Portanto, de acordo com o que ele propõe em 1891, se entendida literalmente, a expressão representação inconsciente não passaria de uma contradição em termos.

No Projeto de uma Psicologia (1995), Freud recusa a identificação entre o psíquico e o consciente e abre espaço em sua teoria para a noção de um psiquismo inconsciente. A estratégia por ele utilizada para incorporar a noção de psíquico inconsciente em sua teoria foi atribuir uma natureza psicológica àqueles processos corticais que, no texto sobre as afasias, eram considerados como sendo concomitantes aos fenômenos psíquicos, e deslocar o paralelismo, que, em (Freud, 1891), definia a relação entre os processos nervosos e os psíquicos, para entre os processos psíquicos inconscientes e os conscientes. Ele propõe, então, que os fenômenos conscientes são paralelos a uma parte dos processos nervosos, aqueles que constituiriam o psíquico inconsciente e, consequientemente, que toda representação consiste num processo associativo cortical totalmente independente da consciência. Esta última passa, assim, a ser concebida como algo posterior e restrito em relação à atividade representacional. $O$ conceito de representação de palavra é retomado, no Projeto, com o objetivo de esclarecer como é possível ocorrer a rememoração de uma representação. Freud estabelece aí um vínculo entre a representação de palavra e a consciência, o qual é resgatado em momentos posteriores, como no artigo O Inconsciente de 1998. Não só estes textos, como também boa parte do restante da metapsicologia freudiana, podem, dessa maneira, ser considerados como herdeiros das idéias apresentadas em Sobre a concepção das afasias e como resultado da ampliação e do desenvolvimento das teses ali propostas.

\section{Referências Bibliográficas}

Amacher, P. (1965). Freud's neurological education and its influence on psychoanalitic theory. Em: Psychological Issues, 14, n.4.

Forrester, J. (1983). A linguagem e as origens da Psicanálise (E.P. Moura, Trad.). Rio de Janeiro: Imago.

Freud, S. (1973). La Afasia. Buenos Aires: Nueva Visión.

Freud, S. (1995). Projeto de uma Psicologia. Rio de Janeiro: Imago.

Freud, S. (1998). Lo Inconsciente (Sigmund Freud Obras Completas. Buenos Aires: Amorrortu Editores, vol. XIV, pp. 153-214.

Herrnstein, R.J. \& Boring, E.G. (1971). Textos básicos de história da psicologia. São Paulo: Editora da Universidade de São Paulo.

Jackson, J.H. (1958). On affections of speech from disease of the brain. Em J. Taylor (Org.), Select Writings of John Hughlings Jackson (vol. 2, pp. 155-170). New York: Basic Books.

Jackson, J.H. (1958). Evolution and dissolution of the nervous system. Em J. Taylor (Org.), Select Writings of John Hughlings Jackson (vol. 2, pp. 45-118). New York: Basic Books.

Marx, O.M. (1967). Freud and Aphasia: An Historical Analysis. American Journal Psychiatry, 124:6, 815-825.

Mill, J.S. (1974). Um exame da filosofia de Sir William Hamilton. São Paulo: Abril Cultural.

Wernicke, C. (1977). The Aphasia Symptom complex. Em G.H. Eggert (Org.), Wernicke's Works on Aphasia (pp.91-145). Nevertheless: Mouton. 


\section{Fátima Caropreso}

Wernicke, C. (1977). Recents Works on aphasia. Wernicke's works on aphasia.

Obs.: Este artigo está relacionado à dissertação de mestrado "Representação e consciência na obra inicial de Freud", desenvolvida junto ao PPG em Filosofia da UFSCar.Fapesp.

\section{Apoio FAPESP.}

